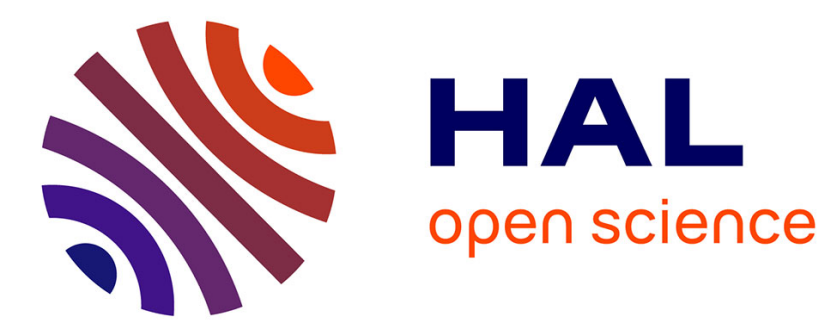

\title{
In-Situ calibration of POCIS for the sampling of polar pesticides and metabolites in surface water
}

Imtiaz Ibrahim, Anne Togola, Catherine Gonzalez

\section{To cite this version:}

Imtiaz Ibrahim, Anne Togola, Catherine Gonzalez. In-Situ calibration of POCIS for the sampling of polar pesticides and metabolites in surface water. Talanta, 2013, 116, pp.495-500. 10.1016/j.talanta.2013.07.028 . hal-00851490

\section{HAL Id: hal-00851490 https: / hal-brgm.archives-ouvertes.fr/hal-00851490}

Submitted on 29 Aug 2013

HAL is a multi-disciplinary open access archive for the deposit and dissemination of scientific research documents, whether they are published or not. The documents may come from teaching and research institutions in France or abroad, or from public or private research centers.
L'archive ouverte pluridisciplinaire HAL, est destinée au dépôt et à la diffusion de documents scientifiques de niveau recherche, publiés ou non, émanant des établissements d'enseignement et de recherche français ou étrangers, des laboratoires publics ou privés. 
2 In-Situ calibration of POCIS for the sampling of polar

4

5

6

7 pesticides and metabolites in surface water

\author{
Imtiaz Ibrahim $^{\mathrm{a}, \mathrm{b}}$, Anne Togola ${ }^{\mathrm{a}}$, Catherine Gonzalez ${ }^{\mathrm{b}}$. \\ $\mathrm{a}^{*}$ Bureau de recherche géologiques et minières, Laboratory division, 3 avenue Claude \\ Guillemin, 45100 Orléans, France. \\ b* Ecole des mines d'Alès, LGEI Center, 6 Avenue de Clavieres, 30319 Alès, France.
}

Authors

I. Ibrahim

${ }^{a}$ Bureau de recherche géologiques et minières (BRGM), Laboratory Division, 3 avenue Claude Guillemin, 45100 Orléans, France

${ }^{b}$ Ecole des mines d'Alès (EMA), LGEI Center, 6 Avenue de Clavieres, 30319 Alès, France i.imtiaz@mines-ales.fr

Tel: (+33)4.66.78.27.22; Fax: (+33)4.66.78.27.01

\title{
A. Togola
}

${ }^{a}$ Bureau de recherche géologiques et minières (BRGM), Laboratory Division, 3 avenue Claude Guillemin, 45100 Orléans, France

a.togola@brgm.fr

Tel: (+33)2.38.64.38.36; Fax: (+33)2.38.64.39.25.

C. Gonzalez

${ }^{b}$ Ecole des mines d'Alès (EMA), LGEI Center, 6 Avenue de Clavieres, 30319 Alès, France catherine.gonzalez@mines-ales.fr

Tel: (+33)4.66.78.27.65; Fax: (+33)4.66.78.27.01 
32

33

\section{Abstract}

Over the past years, passive sampling devices have been successfully used for the monitoring of various pollutants in water. The present work studied the uptake kinetics in surface water of ten polar pesticides and metabolites, using pharmaceutical POCIS samplers. The aim was to determine sampling rates from in-situ calibration and to compare results with those obtained earlier under laboratory conditions, with the final objective of assessing the impact of environmental conditions on POCIS field performance. Field results showed a low efficiency of POCIS uptake capacity for moderately polar compounds, such as propiconazole $\left(\log \mathrm{K}_{\mathrm{ow}}=3.72\right)$ and tebuconazole $\left(\log \mathrm{K}_{\mathrm{ow}}=3.7\right)$, that were present in the aqueous phase at very low levels. The in-situ sampling rates obtained in this study ranged from 169 to $479 \mathrm{~mL} \mathrm{~g}^{-1}$ day $^{-1}$ and differ by a factor of 3 to 7.5 from Rs determined under laboratory conditions.

\section{Highlights}

- In-situ calibration of POCIS

- Sampling rate determination of pesticides and metabolites

- Comparison of sampling rate obtained under in-situ and laboratory conditions

- Environmental factors influencing the uptake rate of POCIS samplers

\section{Keywords}

POCIS, in-situ calibration, pesticides and metabolites 


\section{Introduction}

Pesticide pollution of the aquatic environment is among the most widely discussed topics in environmental issues. The determination of ecotoxicological risk for these compounds requires regular monitoring for assessing the water quality. Traditional environmental monitoring programs are based on the collection of several spot samples at specific sites at fixed time intervals and using expensive analytical methods. Contaminant concentrations can vary over time and such traditional monitoring strategies may miss fluctuations in pollutant levels; moreover, they are sometimes not efficient for detecting and quantifying micropollutants present in ultra-trace to trace levels in water[1]. Over the past years, passive sampling devices have been successfully used for the monitoring of various pollutants in surface- and ground-waters [1]. The principle of passive sampling in water has been well described in the literature [2]. Several designs of such devices are available either as experimental prototypes or as commercial [3]. Today, two main passive samplers are used for polar organic contaminants: the polar organic integrative sampler (POCIS) and the Chemcatcher with a polar configuration, but other tools are under investigation, such as $\mathrm{O}$ DGT [4] or silicon [5]. Chemcatcher is composed of a polytetrafluoroethylene or polycarbonate body with a polyethersulfone (PES) hydrophilic microporous membrane, coupled with various receiving phases, such as C18 Empore disk [3, 6], SDB-XC [7, 8], or SDB-RPS $[9,10]$. The POCIS consists of a solid sequestration phase (sorbent) between two PES membranes [11]. This sampler can retain a wide range of polar organic pollutants, such as pesticides, non-ionic detergents, polar pharmaceuticals, or natural and synthetic hormones $[12,13]$. Due to their high capacity for accumulating target pollutants, passive samplers have contributed to decreasing the detection limits of analytical methods, and can be used as a quantitative tool for determining time-weighted average (TWA) concentrations for a given compound and over a specific period [14].

In order to estimate the TWA water concentrations of pollutants from accumulated amounts in a passive sampler used in kinetic mode, laboratory or in-situ calibration data are required for estimating the sampling rate (Rs) for each compound. The Rs of passive samplers depends on the physico-chemical properties of the chemicals (e.g. molecular weight, structure and hydrophobicity) and on environmental conditions, such as temperature [6, 15], water flow rate/turbulence $[7,8,16]$ and dissolved organic carbon [17-19]. The challenge is to obtain TWA concentrations that are sufficiently representative of the real pollution levels in the aquatic medium. This goal is mainly dependent upon the calibration of the passive sampler, 
generally done under controlled conditions at laboratory scale. However, as the field environment could be variable and also very different from fixed laboratory conditions, the use of inappropriate laboratory-derived sampling rates for calculating TWA concentrations from passive samplers exposed in the field, can lead to an inaccurate evaluation of the real pollution levels [20-24] with higher (about 4 times) or lower (about 3 times) concentrations when comparing TWA and grab concentrations. In order to obtain representative concentrations from a passive sampler, it is necessary to correct the laboratory-sampling rates (Lab-Rs) for considering the exposure conditions. The proposed rectification tools are still under investigation to correct laboratory sampling rate or determining in-situ sampling rates, that are representative of the uncontrolled and variable field conditions, allowing to calculate realistic TWA concentrations $[2,25,26]$.

Performance reference compound (PRC) approach was first proposed and demonstrated for semi-permeable membrane devices (SPMDs[28, 29]) [27, 28]. The possibility of using PRCs for Chemcatcher has been evaluated and validated for its hydrophobic configuration [26]. So far no field studies have evaluated the performance of these compounds for correcting the laboratory-sampling rates and for obtaining reliable concentrations from the polar Chemcatcher configurations. Up to now, very few PRCs have been tested for POCIS samplers $[11,22]$. However, further improvement and validation are needed for using PRC.

The Passive Flow monitor [29] is another approach for considering environmental variations. This tool is based on the dissolution of gypsum for measuring the average water velocity to which a sampler has been exposed.

In order to understand the influence of environmental conditions on passive sampling, and to validate in-situ POCIS performance, another approach consists in deploying the samplers in the field for determining the in-situ Rs values by measuring simultaneously target-compound concentrations in water and in the samplers during the exposure period. However, this method requires the presence of quantifiable levels of target compounds in the studied medium that should remain relatively constant throughout the exposure period. To date, only few values of in-situ Rs for POCIS have been published [12, 23, 30, 31].

The aim of the present work was threefold: 1) Study the uptake kinetics in surface water of a range of polar pesticides and metabolites by pharm-POCIS samplers, in order to determine sampling rates by in-situ calibration. 2) Compare these results with those obtained previously under laboratory conditions for assessing the impact 
of environmental conditions on POCIS field performance. 3) Evaluate the

120 effectiveness of POCIS for determining TWA concentrations in the aquatic medium, compared with the classical spot sampling method.

All analytical standards (purity $>98 \%$ ) were purchased from Dr. Ehrenstorfer (CIL, SainteFoy-La Grande, France), including deuterated labeled compounds, and atrazine-d5 (97.5\%) and simazine-d10 (98\%) that were used for recovery and analytical control, respectively. Acetonitrile and methanol (HPLC reagent grade) were obtained from Fisher Chemical. Water used for experimental processes was generated from a Millipore Direct-Ultrapure Water Systems. Oasis ${ }^{\mathrm{TM}}$ HLB extraction cartridges $(500 \mathrm{mg}, 60 \mu \mathrm{m})$ were purchased from Waters Corporation and a Visiprep SPE vacuum manifold was used for water samples extractions.. $\mathrm{GF} / \mathrm{F}$ glass-fiber filters $(0.7 \mu \mathrm{m}$ pore size) were from Whatman (Maidstone, England), and the POCIS were purchased from Exposmeter SA (Tavelsjö, Sweden). These were of the pharmaceutical configuration, each filled with approximately $230 \mathrm{mg}$ Oasis ${ }^{\mathrm{TM}}$ HLB sorbent and having a sampling surface area of $41 \mathrm{~cm}^{2}$. Empty polypropylene SPE tubes with polyethylene frits were purchased from Supelco (Bellefonte, USA).

\subsection{Site selection and sampling strategy}

The sampling area for the study is located in the Bas-Rhône Languedoc (BRL) canal, in a water-pumping station on the Rhône River in Bellegard (Gard Dept). The BRL canal is an irrigation canal bringing water from the Rhône River to the south of the Gard and the east of the Herault departments. The Rhône water is taken upstream of Arles city and is led by a $12-\mathrm{km}$ channel to the pumping station. This station allows the irrigation of more than 36,000 hectares of agricultural land in southern France. This water is also used in six watertreatment plants for the production of drinking water. Water quality monitoring realized by BRL revealed the presence of some pesticides in the water at relatively constant levels over a long enough period to provide reliable sampling rates.

The present field campaign took place at Pichegu station for three weeks (20 February to 14 March 2012). On the day of deployment, the samplers were placed in homemade cages built with a mesh that lets water run through without changing the water flow within the cage. Each cage contained two POCIS. During transport to the field, the cages were covered with 
aluminum-foil sheets in order to minimize contamination. On site, the six cages were submerged simultaneously at a depth of $1 \mathrm{~m}$. In order to maintain this position, each cage was tied with a rope fixed to a metal barrier.

In order to validate the applicability of the laboratory and the in situ sampling rates (Lab-Rs and in situ-Rs) for the determination of reliable $\mathrm{C}_{\mathrm{TWA}}$, an independent campaign was run from 29 June to 19 July 2012. During this period, Pharm-POCIS were deployed in triplicates for 20 days in the Aristide Dumont pumping station, and three water samples were taken at different times during the campaign.

\subsection{Sampler retrieval and water sampling}

On the day of deployment, two grab water samples of one liter were collected in cleaned amber glass bottles on the spot where each cage was immersed. In order to study the pesticide-uptake kinetics of the samplers, one cage was removed from the water after 3, 7, 10, 14, 17 and 21 days after deployment. A duplicate water sample was collected at the same time. A field blank was used as quality control, being transported to the site and exposed to the air each time the immersed samplers were retrieved from water. The retrieved POCIS samplers were rinsed with ultrapure water, wrapped in aluminum foil, placed in a plastic bag and stored under cooled conditions during transport to the laboratory. In order to assess the influence of environmental conditions on the POCIS sampling efficiency, the water flow velocity -measured by current meter (HYDREKA, model 801, Saint Cyr au Mont d'Or, France)- and the physico-chemical parameters of the water were monitored during the different field visits. The physico-chemical parameters were obtained with a Pastel UV portable spectrophotometer (SECOMAM), which, through spectral deconvolution, simultaneously estimates general (COD, BOD, TOC, SM) parameters. The simultaneous analysis of nitrate and orthophosphate was done by ionic chromatography with an IC-PAK A HR WATERS column with borate/gluconate as eluent at $1.0 \mathrm{~mL} \mathrm{~min}^{-1}$, detected with a conductivity detector (WATERS). Conductivity and $\mathrm{pH}$ were measured in-situ with specific probes.

\subsection{Extraction of analytes from water samples and POCIS samplers}

The pesticides were usually extracted on the same day the samplers were retrieved. The collected $1 \mathrm{~L}$ water samples were filtered through GF/F filters to eliminate suspended matter, spiked with $100 \mathrm{ng}$ of d5-atrazine, and extracted via solid phase extraction (SPE) using an Oasis ${ }^{\mathrm{TM}}$ HLB cartridge. 
Prior to extraction, the Oasis HLB cartridges were activated with $5 \mathrm{~mL}$ of acetonitrile under vacuum, followed by $5 \mathrm{~mL}$ of methanol and $5 \mathrm{~mL}$ of ultrapure water. The water samples were


The cartridges were then dried under vacuum for one hour before eluting the pesticides with $8 \mathrm{~mL}$ of acetonitrile, which was concentrated to $1 \mathrm{~mL}$ under a nitrogen stream. In the laboratory, each POCIS was opened on one side by cutting the PES membrane. The sorbent was then transferred into an empty solid-phase extraction tube packed with polyethylene (PE) frits of $20 \mu \mathrm{m}$ porosity. The SPE tubes were then put on a Visiprep SPE vacuum manifold for drying the Oasis ${ }^{\mathrm{TM}}$ HLB solid phase for 30 minutes under vacuum. Prior to extraction, $75 \mu \mathrm{L}$ of atrazin-d5 $\left(0.5 \mathrm{mg} \mathrm{L}^{-1}\right)$ was added to the sorbent. The pesticides were extracted by eluting under vacuum with $8 \mathrm{~mL}$ of acetonitrile. The eluate was reduced to $1 \mathrm{~mL}$ in a gentle stream of nitrogen and transferred to an autosampler vial for analysis. Field blanks were treated in the same manner as the deployed samplers. All extracts were spiked with $50 \mu \mathrm{L}$ of deuterated internal standard simazine-d5 (2 $\left.\mathrm{mg} \mathrm{L}^{-1}\right)$ and analyzed by UPLC-MS/MS.

\subsection{Chemical analysis}

The passive samplers and spot water-sample extracts were analyzed by UPLC-MS/MS. Chromatographic separation was done with a Waters ACQUITY UPLC system (Waters, Guyancourt, France) using a $150 \mathrm{~mm} \times 2.1 \mathrm{~mm} \times 1.7 \mu \mathrm{m}$ ACQUITY BEH C18 column. The mobile phase was composed of water $(0.05 \%$ formic acid $)$ and acetonitrile $(0.05 \%$ formic acid) at a constant flow of $0.4 \mathrm{mLmin}^{-1}$. The gradient was programmed to increase the amount of acetonitrile from $0 \%$ to $100 \%$ in $7.5 \mathrm{~min}$, with stabilization at $100 \%$ for $1.5 \mathrm{~min}$ before returning to the initial conditions in $0.3 \mathrm{~min}$. These conditions were maintained for $15 \mathrm{~min}$. Mass spectrometry detection was done with a Quattro Premier XE MS/MS (Waters, Guyancourt, France), equipped with an ESI interface and controlled by MassLynx software. The ESI polarity ionization was set to the positive mode (ESI+). Mass spectra were generated in the multiple reaction-monitoring mode (MRM); their acquisition for each compound was done by registering two characteristic fragments; one transition was used for quantitation and the other one for confirmation.

\section{6. $\underline{\mathbf{R}}_{\underline{s}}$ calculation}

For an exposure time corresponding to the linear uptake region, the amount of analyte accumulated in the sampler can be resumed by equation (1): 
223 where Ms is the amount of the analyte accumulated in the sampler (ng) after exposure, $\mathrm{Ms}_{0}$ the amount of the analyte in the sampler before exposure, $\mathrm{C}_{\mathrm{TWA}}$ is the time-weighted average (TWA) concentration of the compound in water ( $\mathrm{ng} \mathrm{L}^{-1}$ ) during the sampling time $\mathrm{t}$ (day), Rs is the sampling rate of the sampler $\left(\mathrm{L} \mathrm{day}^{-1}\right)$ representing the equivalent extracted water volume per unit of time for a given compound.

If analyte concentrations in the aqueous medium remain constant during the calibration campaign, the sampling rate for each compound can be calculated with equation (1). This is done by dividing the slope of the linear curves describing the pollutant accumulation in POCIS samplers by their respective mean concentrations in the aqueous phase calculated from the 14 water samples taken during the 21 days of campaign.

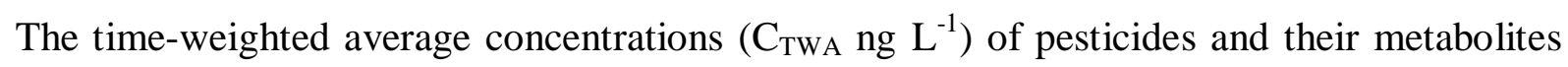
are calculated with equation (1) from the amount of analyte accumulated in the sampler exposed in the aqueous phase for 21 days, which is determined after extraction and UPLCMS/MS analysis.

\section{Results and discussion}

\subsection{Water sample analyses}

The water temperature and conductivity measured during the field experiment ranged respectively from 5 to $10{ }^{\circ} \mathrm{C}$ (average temperature of $8.4 \pm 2.4 ; \mathrm{n}=7$ ) and from 410 to $464 \mu \mathrm{S}$ $\mathrm{cm}^{-1}$. The quality of the aqueous medium did not significantly change during the 21-day trial (data presented in Supplementary Materials). The average water velocity measured near the cages at a depth of $1 \mathrm{~m}$ was around $2.6 \mathrm{~cm} \mathrm{~s}^{-1}$.

Overall, 13 compounds were detected in the water samples, including triazines (atrazine, simazine, terbuthylazine), phenylureas (isoproturon IPU; diuron, chlortoluron), conazoles (tebuconazole, propiconazole), chloroacetanilides (metolachlor), phenylamides (metalaxyl) and triazine metabolites (deethylatrazine DEA, deisopropylatrazine DIA, deethylterbuthylazine DET). Most of these compounds occurred at very low levels $\left(<8 \mathrm{ng} \mathrm{L}^{-1}\right)$ in the water samples. Among the quantified compounds, reasonably stable water concentrations were obtained for most during the 21-day trial (Table 1). Five compounds had very stable concentrations in water $\left(\mathrm{C}_{\mathrm{w}}\right)$ with a coefficient of variation $(\mathrm{CV})$ below $10 \%$ and six compounds had fairly stable $\mathrm{C}_{\mathrm{w}}$ values, with a $\mathrm{CV}$ between 10 and $20 \%$. However, 
considerable variation was observed for the metolachlor concentration $(\mathrm{CV}=69 \%)$ and tebuconazole $(\mathrm{CV}=41 \%)$ over the exposure period (Table 1$)$. The concentration profile of metolachlor showed a variation between 2.5 and $27 \mathrm{ng} \mathrm{L}^{-1}$ with a peak detected from the $7^{\text {th }}$ to the $10^{\text {th }}$ day of exposure, after which the concentration decreased to $10 \mathrm{ng} \mathrm{L}^{-1}$ (Fig.1a).

\subsection{Accumulation of pesticides in POCIS samplers}

At the end of the field trial, POCIS analyses showed the presence of the 13 compounds previously quantified in the water samples. For most of those compounds, their accumulation by the POCIS samplers was gradual and linear over the experimental 21-day period (Table 1). Uptake in POCIS was fitted with a simple linear regression model without zero-intercept. Linear fits were not forced through zero in order to well describe the accumulation of targeted compounds in the sampler. Linear fits were not forced through zero in order to well describe the accumulation of target compounds in the sampler.

Linear regression correlation coefficients $\left(\mathrm{R}^{2}\right)$ were in the range of $0.8302-0.9860$ (Table 1). When looking at the accumulation trend of atrazine and its metabolite DIA (Fig. 1b and 1c), we see a linear accumulation of atrazine in POCIS for the 21 days, while the accumulation of DIA follows a curvilinear pattern. In fact, DIA is linearly accumulated during the first seven days of exposure, after which its accumulation curve tends to a curvilinear phase, modeled with a second-order polynomial function $\left(\mathrm{R}^{2}=0.7844\right)$. A similar observation was made during laboratory calibration of POCIS for sampling polar pesticides and metabolites [32]. For the metolachlor, accumulation in the sampler followed a linear pattern with a slight increase in accumulation between days 10 and 14, which is the interval corresponding to the appearance of the metolachlor concentration peak in the aqueous phase. As the duration of the pollution event was quite short compared to the total exposure time of the sampler, this peak of concentration was smoothed and integrated by the POCIS. It could be noted that the mass of metolachlor in POCIS for 3 days exposure was under the limit of quantification (Fig. 1a).

The two less polar compounds, propiconazole $(\log K=3.72)$ and tebuconazole $(\operatorname{logKow}=3.7)$, were only found at quantifiable levels in POCIS sampled during 17th and the 21th exposure days, respectively, for which reason it was not possible to determine in-situ Rs values for these compounds. However, different phenomena could explain these results. The sorption of these compounds onto natural organic matter, generally controlled by their hydrophobicity 
and characterized by the octanol-water partition coefficient $\left(\mathrm{K}_{\mathrm{ow}}\right)$, could limit their accumulation by the sampler membrane surface (pore size $100 \mathrm{~nm}$ ), although several studies $[7,26]$ have classified compounds with $\log \mathrm{K}_{\mathrm{ow}}$ between 2.5 and 4.3 as slightly hydrophilic with a medium sorption potential onto organic matter. Among the 13 compounds detected in water, seven compounds have a $\log \mathrm{K}_{\mathrm{ow}}>2.5$ (diuron, atrazin, IPU, metolachlor, terbuthylazine, tebuconazole, propiconazole) with a $\log \mathrm{K}_{\mathrm{ow}}$ in the range of 2.68-3.72. However, the $\mathrm{K}_{\mathrm{ow}}$ does not only drive the sorption of chemicals onto organic matter. Other parameters, such as the nature and chemical structure of the organic matter and the $\mathrm{pH}$ of the aqueous phase, can affect the sorption process of pollutants onto natural organic matter in water [33].

Another phenomenon that can limit the accumulation of these compounds by POCIS is the different barrier resistance to the mass transfer of contaminants in the sampler, for instance, the water boundary layer (WBL), the diffusion membrane resistance and the biofilm resistance in a case of biofouling phenomenon [6]. [35]An increase in hydrodynamic turbulence reduces the resistance of the WBL and thus increases the accumulation of analyte in the sampler.

A lag time is attributed to the time it takes for the compound to pass through the diffusive barriers (WBL, PES diffusion membrane and biofilm in case of bio-fouling) before it can be detected in the sorbent phase.

A lag time occurs if a steady-state condition across these layers is not rapidly established. Vermeirssen et al. [34] noticed an increase in the $\mathrm{C}_{\mathrm{PES}} / \mathrm{C}_{\text {sorbent }}$ ratios with $\log \mathrm{K}_{\mathrm{ow}}$ of studied compounds. Compounds with higher $\log \mathrm{K}_{\mathrm{ow}}$ values tended to be retained more by the PES membrane. High levels of absorption into PES correlated with a delay in transfer of the compound from water through the PES to the sorbent. For POCIS, [35] reported the occurrence of a lag-phase for compounds with $\log \mathrm{K}_{\mathrm{ow}}$ values exceeding 3.1.

\subsection{In-situ sampling rates and comparison with lab- $\mathbf{R}_{\mathrm{s}}$}

Table 1 presents the in-situ sampling rates expressed in $\mathrm{mL} \mathrm{g}^{-1}$ day $^{-1}$ of pesticides and those determined previously under controlled laboratory conditions [32]. The calculated in-situ- $\mathrm{R}_{\mathrm{s}}$ values ranged from 169 to $479 \mathrm{~mL} \mathrm{~g}^{-1}$ day $^{-1}$. The $\mathrm{R}_{\mathrm{s}}$ of metolachlor was calculated: despite a significant variability of its aqueous concentration during the experiment caused by a pollution peak, accumulation of this pesticide in the sampler followed a linear pattern 
(Fig. 1a). For most of the compounds, the field-sampling rates were significantly lower-bya factor of 3-5-than those of the laboratory experiment, except DET that had a ratio of 7.5 (Table 1). During the field experiment, the accumulation of DET by POCIS was very slow compared to the other compounds, which explains the obtained ratio (Rs-lab/Rs in-situ). The laboratory calibration experiment was conducted at $21{ }^{\circ} \mathrm{C}$ with a relatively high flow velocity $\left(11.5 \mathrm{~cm} \mathrm{~s}^{-1}\right)$ [32]. The low water turbulence observed in the field, $\left(2.6 \mathrm{~cm} \mathrm{~s}^{-1}\right)$, can affect analyte accumulation in POCIS. Previous studies at laboratory scale showed that hydrodynamics significantly affect analyte uptake by POCIS, particularly between exposure conditions conducted while stirring or under quiescent conditions [17].[38] Rs values calculated from these two exposure conditions differ by a factor of 3-6 for most of the tested compounds. [17]Water turbulence increases the mass-transfer coefficient $\left(\mathrm{k}_{0}\right)$, and thus Rs, by reducing the thickness of the diffusion boundary layer. An effect of hydrodynamic variation on Rs was observed in several earlier studies involving SPMD and Chemcatcher samplers [7, $8,26,28]$.

A low water temperature can affect the mass transfer of analytes from water to POCIS through decreasing their uptake kinetics. The water-temperature dependency of uptake for polar compounds was investigated for the polar Chemcatcher, which demonstrated an increase in sampling rates by a factor of 2 over a $20{ }^{\circ} \mathrm{C}$ temperature range [36]. Few studies, concerning the effect of temperature on the uptake of organic contaminants by POCIS samplers has been published in the literature [40][37], showing an increase in the POCIS sampling rate for most of the pharmaceutical compounds tested between 5 and $21^{\circ} \mathrm{C}$. [41] The type of water used for the calibration may also influence the accumulation of target compounds in POCIS. The impact of the water matrix effect on POCIS sampling rates for pharmaceuticals showed great differences when comparing deionized water, tap water and natural lake water [19].

\subsection{Applicability of Rs for determining $\mathbf{C}_{\mathrm{TWA}}$}

The water velocity during this second campaign was below $2.5 \mathrm{~cm} \mathrm{~s}^{-1}$ and the mean value of the water temperature was $27.2^{\circ} \mathrm{C}(27.2 \pm 1 ; n=3)$.

The results of the analysis of POCIS and water samples revealed the presence 8 compounds in the aqueous phase, including triazines and metabolites (atrazine, simazine, terbuthylazine and 
DEA), phenylureas (diuron, chlortoluron), chloroacetanilides (metolachlor), phenylamides (metalaxyl).

The $\mathrm{C}_{\mathrm{TWA}}$ of the detected compounds was calculated from the mass accumulated in POCIS samplers after 20 days exposure using Rs-lab and Rs in-situ. The values were compared with the average water concentrations obtained from spot samples over the 20 days (Fig. 2). Comparison of the data obtained from these two sampling methods shows that the use of Rs Lab does not permit to obtain reliable values of concentrations. This is certainly due to the high difference of the water turbulence between field and laboratory conditions. Because lab conditions (in particular flow velocity) influence uptake rates, the calculated concentrations are not in accordance with the spot sampling concentrations (average water concentrations over 20 days). In this case, concentrations are underestimated by a factor ranging between 3 and 5. The applicability of POCIS sampling rates determined under field conditions to calculate reliable $\mathrm{C}_{\mathrm{TWA}}$ of pesticides in the channel BRL showed good results. The use of insitu Rs permits to obtain a better representativity of the real levels of pesticides in water.

\section{Conclusions}

The field calibration of pharmaceutical configuration POCIS samplers was done in a channel network where water comes from Rhône river water. The BRL canal was used as a full-scale pilot site, where physico-chemical parameters, flow velocity and temperature were monitored. Based on those experimental conditions, we determined the in-situ sampling rates of some polar pesticides and their associated metabolites found in the water. Calibration results revealed integrative linear uptakes of ten compounds over a 21-day exposure period, except DIA, whose accumulation in POCIS followed a curvilinear pattern. The low variability of water temperature during the exposure period did not affect the integrative uptake of the POCIS sampler, and thus the linear model for determining the accumulation rate (Rs) was successfully applied. Field results showed a low efficiency of the POCIS uptake capacity for moderately polar compounds such as propiconazole $\left(\log \mathrm{K}_{\mathrm{ow}}=3.72\right)$ and tebuconazole $\left(\log \mathrm{K}_{\mathrm{ow}}=3.7\right)$, which were present in the aqueous phase at very low levels. The in-situ sampling rates obtained in this study range from 169 to $479 \mathrm{~mL} \mathrm{~g}^{-1}$ day $^{-1}$ and differ from a factor of 3 to 7.5 with the Rs values determined under laboratory conditions [32]. As shown by this study, the use of laboratory sampling rates for calculating TWA concentrations may lead to a significant underestimation of the real concentration values. 
POCIS samplers can give reliable estimates of ambient pesticide concentrations in water and can provide a holistic picture of the presence of these compounds in the aquatic medium by the use of in-situ sampling rates. Application of in-situ Rs on the same site but on different period has been validated. However, in-situ calibration is still an exploratory approach that needs more data and fieldwork to evaluate its performance and applicability for measuring TWA concentrations in various waters and under different environmental conditions. One line of investigation could be to correct lab-sampling rates by considering the main factor that seems to affect passive sampling accumulation capacity: i.e. flow velocity. The use of a passive flow monitor needs further investigation as well, and a channel with flow control and natural water is a good setting for developing and validating passive samplers as suitable tools.

\section{References}

[1] F. Stuer-Lauridsen, Environ. Pollut. 136 (2005) 503-524.

[2] K. Booij, B. Vrana, J.N. Huckins, In: R. Greenwood, G. Mills and B. Vrana, Editor(s), Comprehensive Analytical Chemistry, Elsevier, 2007, Volume 48 p. 141-169.

[3] B. Vrana, I.J. Allan, R. Greenwood, G.A. Mills, E. Dominiak, K. Svensson, J. Knutsson, G. Morrison, TrAC, Trends Anal. Chem. 24 (2005) 845-868.

[4] C.E. Chen, H. Zhang, K.C. Jones, J. Environ. Monit. 14 (2012) 1523-1530.

[5] K. Wille, M. Claessens, K. Rappé, E. Monteyne, C.R. Janssen, H.F. De Brabander, L. Vanhaecke, J. Chromatogr. A, 1218 (2011) 9162-9173.

[6] R. Greenwood, G. Mills, and B. Vrana (eds), Passive Sampling Techniques in Environmental Monitoring. Comprehensive Analytical Chemistry Series, Elsevier, Amsterdam, 2007.

[7] R. Gunold, R.B. Schafer, A. Paschke, G. Schuurmann, M. Liess, Environ. Pollut. 155 (2008) 52-60.

[8] E.L.M. Vermeirssen, N. Bramaz, J. Hollender, H. Singer, B.I. Escher, Wat. Res. 43 (2009) 903-914.

[9] M. Shaw, G. Eaglesham, J.F. Mueller, Chemosphere, 75 (2009) 1-7.

[10] B.S. Stephens, A.P. Kapernick, G. Eaglesham, J.F. Mueller, Mar. Pollut. Bull. 58 (2009) 1116-1122.

[11] D.A. Alvarez, J.D. Petty, J.N. Huckins, T.L. Jones-Lepp, D.T. Getting, J.P. Goddard, S.E. Manahan, Environ. Toxicol. Chem. 23 (2004) 1640-1648.

[12] C. Harman, I.J. Allan, E.L. Vermeirssen, Environ. Toxicol. Chem. 31 (2012) 27242738.

[13] N. Morin, C. Miège, M. Coquery, J. Randon, TrAC, Trends Anal. Chem. 36 (2012) 144-175.

[14] A. Kot-Wasik, B. Zabiegata, M. Urbanowicz, E. Dominiak, A. Wasik, J. Namiesnik, Anal. Chim. Acta, 602 (2007) 141-163.

[15] B. Vrana, G.A. Mills, M. Kotterman, P. Leonards, K. Booij, R. Greenwood, Ozone at the Intensive Monitoring Plots in SW Europe, 145 (2007) 895-904.

[16] H. Li, E.L. Vermeirssen, P.A. Helm, C.D. Metcalfe, Environ. Toxicol. Chem. 29 (2010) 2461-2469. 
[17] L. Charlestra, A. Amirbahman, D.L. Courtemanch, D.A. Alvarez, H. Patterson, 433 Environ. Pollut. 169 (2012) 98-104.

434 [18] J.N. Huckins, K. Booij, J.D. Petty, Monitors of organic chemicals in the environment:

Semipermeable Membrane Devices, Springer Verlag, New York (2006).

[19] H. Li, P.A. Helm, G. Paterson, C.D. Metcalfe, Chemosphere, 83 (2011) 271-280.

[20] A. Arditsoglou, D. Voutsa, Environ. Pollut. 156 (2008) 316-324.

[21] S. Lissalde, N. Mazzella, V. Fauvelle, F.Â.o. Delmas, P. Mazellier, B. Legube, J. Chromatogr. A, 1218 (2011) 1492-1502.

[22] C. Miege, N. Mazzella, S. Schiavone, A. Dabrin, C. Berho, J.P. Ghestem, C. Gonzalez, J.L. Gonzalez, B. Lalere, S. Lardy-Fontan, B. Lepot, D. Munaron, C. Tixier, A. Togola, M. Coquery, TrAC, Trends Anal. Chem. 36 (2012) 128-143.

[23] Z. Zhang, A. Hibberd, J.L. Zhou, Anal. Chim. Acta, 607 (2008) 37-44.

[24] M.J. Martínez Bueno, M.D. Hernando, A. Agüera, A.R. Fernández-Alba, Talanta, 77 (2009) 1518-1527.

[25] N. Mazzella, J.-F. Dubernet, F. Delmas, J. Chromatogr. A, 1154 (2007) 42-51.

[26] B. Vrana, G.A. Mills, E. Dominiak, R. Greenwood, Environ. Pollut. 142 (2006) 333 -

\section{3.}

[27] K. Booij, H.M. Sleiderink, F. Smedes, Environ. Toxicol. Chem. 17 (1998) 1236-1245.

[28] J.N. Huckins, J.D. Petty, J.A. Lebo, F.V. Almeida, K. Booij, D.A. Alvarez, W.L. Cranor, R.C. Clark, B.B. Mogensen, Environ. Sci. Technol. 36 (2002) 85-91.

[29] D. O’Brien, T. Komarova, J.F. Mueller, Mar. Pollut. Bull. 64 (2012) 1005-1011.

[30] R. Jacquet, C. Miège, P. Bados, S. Schiavone, M. Coquery, Environ. Toxicol. Chem. 31 (2012) 279-288.

[31] N. Mazzella, S. Lissalde, S. Moreira, F. Delmas, P. Mazellier, J.N. Huckins, Environ. Sci. Technol. 44 (2010) 1713-1719.

[32] I. Ibrahim, A. Togola, C. Gonzalez, Environ. Sci. Pollut. R. 20 (2013) 3679-3687.

[33] A. Nikolaou, S. Meric, D. Fatta, Anal. Bioanal. Chem. 387 (2007) 1225-1234.

[34] E.L.M. Vermeirssen, C. Dietschweiler, B.I. Escher, J. Van Der Voet, J. Hollender, Environ. Sci. Technol. 46 (2012) 6759-6766.

[35] C. Harman, K.E. Tollefsen, O. Bøyum, K. Thomas, M. Grung, Chemosphere, 72 (2008) 1510-1516.

[36] R. Greenwood, G.A. Mills, B. Vrana, I. Allan, R. Aguilar-Martinez, G. Morrison, in Passive Sampling Techniques in Environmental Monitoring (Comprehensive Analytical Chemistry), R. Greenwood (Ed.), Elsevier, 2007, p. 199-229.

[37] A. Togola, H. Budzinski, Anal. Chem. 79 (2007) 6734-6741. 
Fig 1 a : Concentrations of metolachlor in water and POCIS over during the 21 day field deployment. Uptake in POCIS was fitted with a simple linear regression model without intercept.

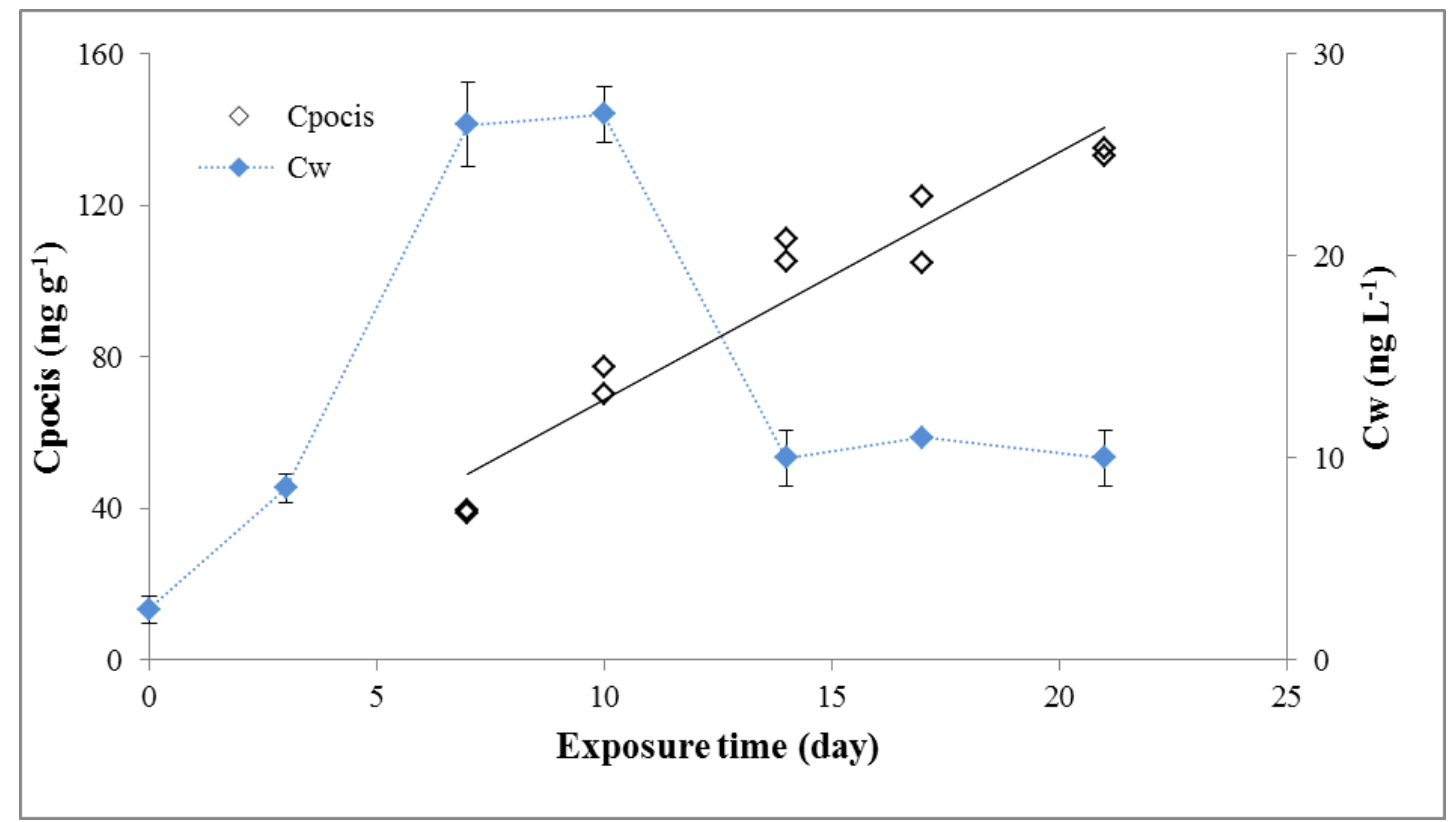

Fig $1 \mathrm{~b}$ : Concentrations of atrazine in water and POCIS over during the 21 day field deployment. Uptake in POCIS was well fitted with a simple linear regression model without intercept.

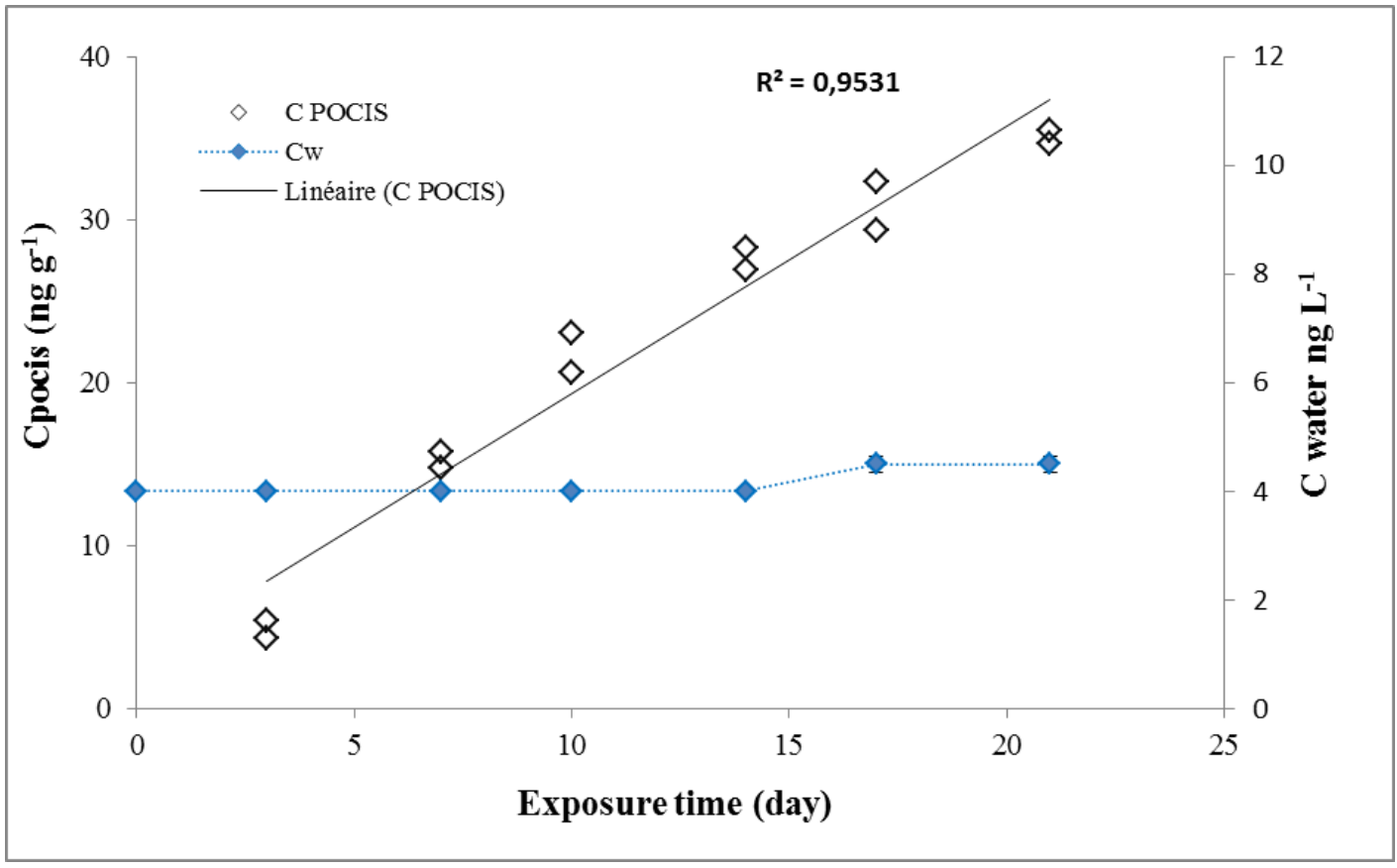


Fig 1 c: Concentration of DIA in water and curvilinear uptake by POCIS during the calibration experiment. Uptake in POCIS was modeled with a second-order polynomial function.

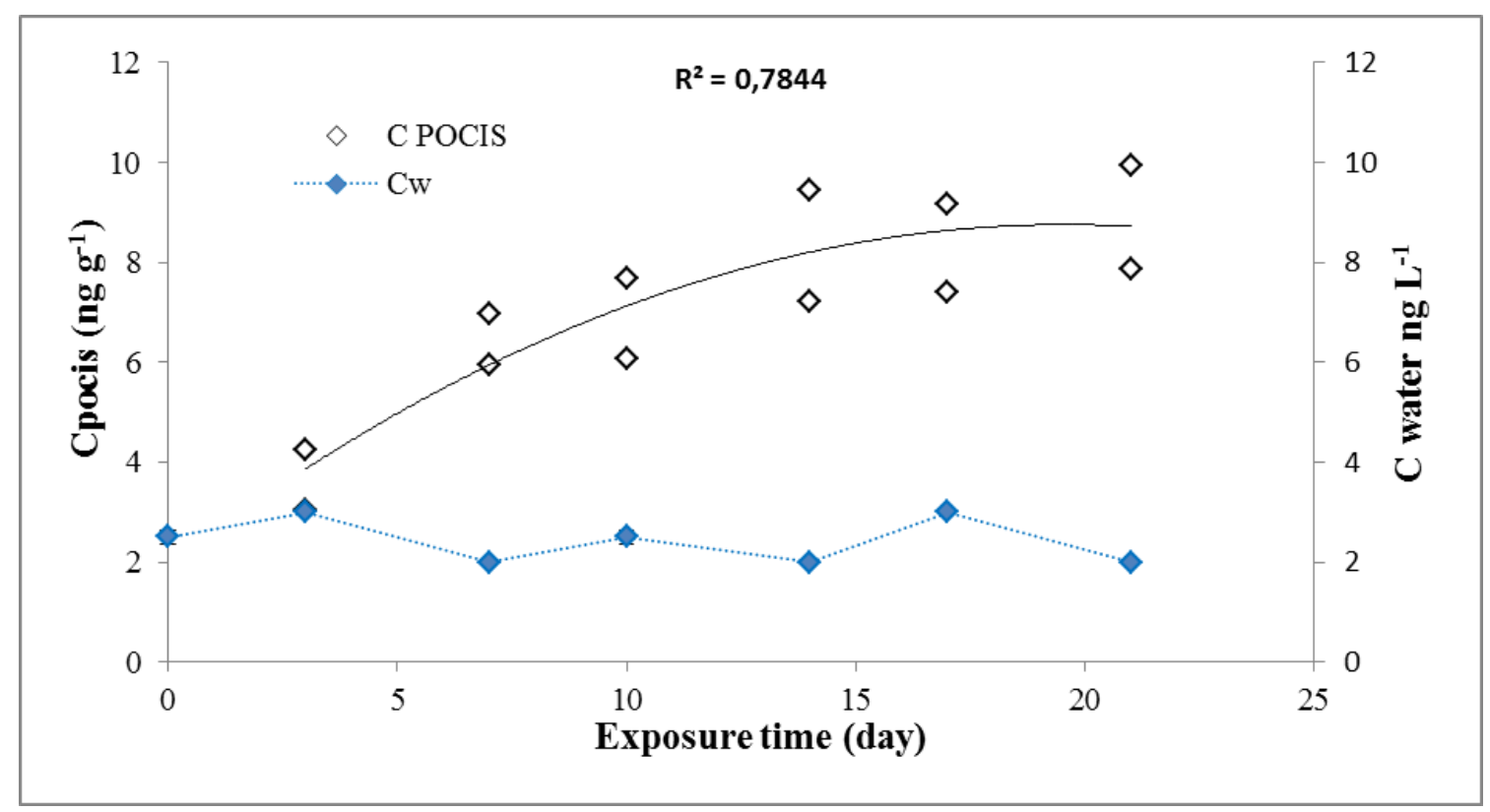

Fig 2: Comparison of TWA concentration from POCIS, calculated from in lab and in situ Rs with average of spot sampling measurements. Average spot sampling $(n=3)$ and CTWA $(n=3)$

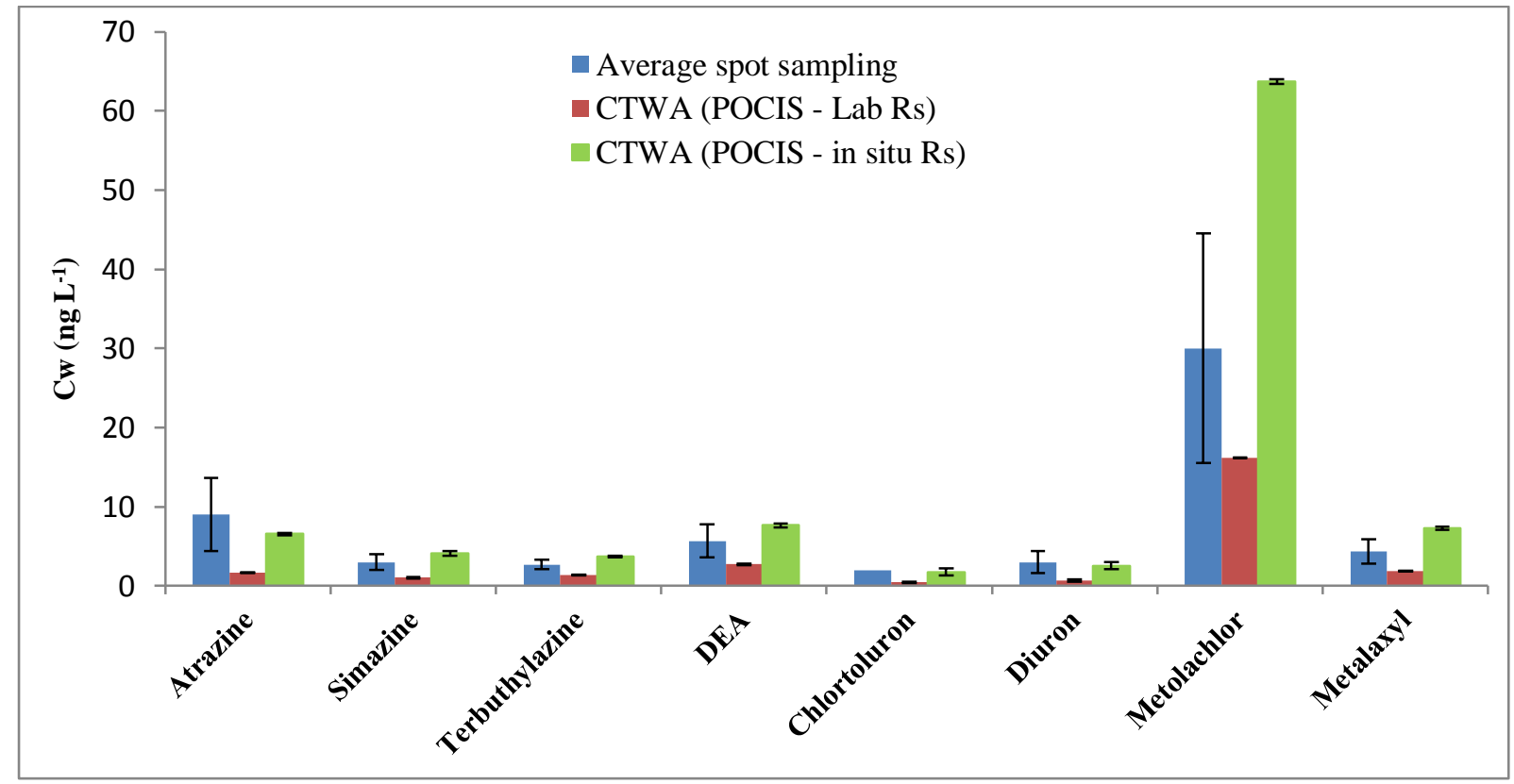


Table 1. Regression lines characterizing analytes uptake in POCIS and average water concentration during in situ calibration study and the Rs -Lab from previous study [구].

\begin{tabular}{|c|c|c|c|c|c|c|c|}
\hline Compounds & LogKow & $\begin{array}{c}\text { Linear regression } \\
\text { lines of uptake } \\
\text { curve }\end{array}$ & $\begin{array}{l}\text { Correlation } \\
\text { coefficient } \\
\left(\mathrm{R}^{2}\right)\end{array}$ & $\begin{array}{c}\text { Mean Cw } \\
(\mathrm{CV}) \\
(\mathrm{n}=12)\end{array}$ & $\begin{array}{c}\mathrm{Rs} \pm \mathrm{SD} \\
\left(\mathrm{mL} \mathrm{g}^{-1} \mathrm{day}^{-1}\right) \\
\text { In-situ }(\mathrm{n}=2)\end{array}$ & $\begin{array}{c}\mathrm{Rs} \pm \mathrm{SD} \\
\left(\mathrm{mL} \mathrm{g}^{-1} \text { day }^{-1}\right) \\
\text { Laboratory } \\
(\mathrm{n}=3)\end{array}$ & $\begin{array}{l}\text { Rs-Lab/Rs } \\
\text { in-situ } \\
\text { ratio }\end{array}$ \\
\hline Atrazine & 2.70 & $y=1,38 x+7$ & 0.9531 & $4.1(6 \%)$ & $333 \pm 24$ & $1269 \pm 174$ & 4 \\
\hline DEA & 1.51 & $y=1,50 x+9,2$ & 0.8695 & $6.4(11 \%)$ & $236 \pm 26$ & $665 \pm 91$ & 3 \\
\hline Simazine & 2.18 & $y=0,66 x+2,1$ & 0.9685 & $2.5(16 \%)$ & $267 \pm 26$ & $1088 \pm 1601$ & 4 \\
\hline Terbuthylazine & 3.21 & $y=0,67 x-0,1$ & 0.9696 & $2.1(9 \%)$ & $319 \pm 62$ & $816 \pm 112$ & 3 \\
\hline DET & 2.30 & $y=0,34 x+6,8$ & 0.8337 & 2 & $169 \pm 47$ & $* 1025 \pm 31$ & 7.5 \\
\hline Chlortoluron & 2.41 & $y=1,36 x+5,3$ & 0.9275 & $5.6(19 \%)$ & $240 \pm 22$ & $1257 \pm 157$ & 5 \\
\hline Diuron & 2.68 & $y=0,97 x+1$ & 0.8302 & $2.4(14 \%)$ & $401 \pm 86$ & $1284 \pm 217$ & 3 \\
\hline IPU & 2.80 & $y=0,65 x+0,3$ & 0.9860 & 2 & $273 \pm 25$ & $1182 \pm 166$ & 4 \\
\hline Metalaxyl & 1.65 & $y=1,12 x+6$ & 0.8811 & $3.9(12 \%)$ & $289 \pm 46$ & $1320 \pm 200$ & 5 \\
\hline Metolachlor & 3.13 & $y=6,53 x+3,5$ & 0.9218 & $13.6(69 \%)$ & $479 \pm 49$ & $1341 \pm 184.6$ & 3 \\
\hline Propiconazole & 3.72 & - & - & 2 & - & - & - \\
\hline Tebuconazole & 3.7 & - & - & $4.1(41 \%)$ & - & - & - \\
\hline
\end{tabular}

\section{SUPPLEMENTARY MATERIAL}

Physicochemical properties of the water column during the campaign

\begin{tabular}{|c|c|c|c|c|c|c|c|c|}
\hline Parameter & Unit & $\mathbf{2 0 / 0 2 / 2 0 1 2}$ & $\mathbf{2 3 / 0 2 / 2 0 1 2}$ & $\mathbf{2 7 / 0 2 / 2 0 1 2}$ & $\mathbf{0 1 / 0 3 / 2 0 1 2}$ & $\mathbf{0 5 / 0 3 / 2 0 1 2}$ & $\mathbf{0 8 / 0 3 / 2 0 1 2}$ & $\mathbf{1 2 / 0 3 / 2 0 1 2}$ \\
\hline Temperature & ${ }^{\circ} \mathrm{C}$ & 4.9 & 5.5 & 8.3 & 10.8 & 10.5 & 10.1 & 8.7 \\
\hline $\mathrm{pH}$ & - & 8.3 & 8.4 & 8.2 & 8.1 & 8.1 & 7.7 & 7.7 \\
\hline Conductivity & $\mu \mathrm{S} \mathrm{cm}^{-1}$ & 422 & 428 & 430 & 410 & 420 & 430 & 464 \\
\hline $\begin{array}{c}\text { Suspend matter } \\
(\mathrm{SM})\end{array}$ & $\mathrm{mg} \mathrm{L}^{-1}$ & 3.8 & 3.6 & 4.7 & 4.2 & 6.7 & 5.7 & 4 \\
\hline $\mathrm{TOC}$ & $\mathrm{mg} \mathrm{L}^{-1}$ & 3.6 & 3.4 & 3.6 & 3.4 & 3.6 & 3.5 & 3.5 \\
\hline $\mathrm{DCO}$ & $\mathrm{mg} \mathrm{L}^{-1}$ & 6.2 & 6.4 & 6.8 & 6.4 & 6.9 & 6.3 & 6.3 \\
\hline $\mathrm{DBO}^{-1}$ & $\mathrm{mg} \mathrm{L}^{-1}$ & 4.7 & 4.5 & 4.8 & 4.8 & 4.5 & 4.8 & 4.6 \\
\hline $\mathrm{NO}_{3}^{-}$ & $\mathrm{mg} \mathrm{L}^{-1}$ & 4.6 & 4.7 & 5.4 & 4.9 & 5.4 & 5.1 & 5 \\
\hline $\mathrm{SO}_{4}^{-}$ & $\mathrm{mg} \mathrm{L}^{-1}$ & 71.1 & 62.6 & 66.8 & 58.2 & 58.2 & 50.3 & 59.9 \\
\hline
\end{tabular}

